\title{
Polymer templated nickel cobaltate for energy storage ${ }^{\star}$
}

\author{
Shaymaa Albohani ${ }^{1,2, *}$, Manickam Minakshi Sundaram ${ }^{2}$, and Damian W. Laird ${ }^{1}$ \\ ${ }^{1}$ Chemical Engineering and Chemistry, School of Engineering and IT, Murdoch University, Murdoch, Australia \\ 2 Electrical Engineering, Energy and Physics, School of Engineering and IT, Murdoch University, Murdoch, Australia
}

Received: 13 January 2017 / Received in final form: 7 July 2017 / Accepted: 11 July 2017

\begin{abstract}
In order to take advantage of the increasing sophistication of technology for harnessing renewable energy resources, serious attention must be paid to how to store and re-access this energy. Electrochemical storage, in the guise of batteries, supercapacitors and pseudocapacitors, has attracted much attention as a viable option for enhanced energy storage applications. But in order for these technologies to be implemented successfully we need to find materials that perform better and are relatively easy to synthesise. Bimetallic transition metal oxides are materials that are readily synthesised and may be multifunctional, i.e. have a role at the electrochemical atomic level as well as the device level. In order for these materials to work efficiently in new generation systems based on sodium and lithium they also need to be mesoporous. This can be achieved by trying to find synthetic techniques that produce specific, highly regulated nanostructures or by adding a 'templating' agent during the bulk synthesis step. We have investigated the simple hydrothermal preparation of a number of nickel cobaltate $\left(\mathrm{NiCo}_{2} \mathrm{O}_{4}\right)$ materials using polymer templates, eggshell membrane (ESM) and poly methyl methacrylate (PMMA), as potential electrode materials for supercapacitors. The ESM was expected to act as a fibrous, random polymeric template while the PMMA should produce a much more ordered material. Electrochemical testing showed that the different templates have led to changes in material morphology and these have resulted in a difference in electrochemical properties. Templated materials increased specific capacitance compared to non-templated and the choice of template could influence the capacitance by as much as $30 \%$.
\end{abstract}

\section{Introduction}

The demand for advanced electrochemical energy storage devices with increased power and energy densities is increasing due to sustainable energy and environmental issues. Electrical energy storage and conversion systems such as fuel cells, batteries and supercapacitors will play a significant role in the effective utilisation of clean energy sources (e.g. wind and solar) with intermittent energy output. Supercapacitors have attracted extensive attention for this role due to their ability to convert chemical energy to electrical energy with high efficiency and excellent cyclic stability [1,2]. In addition, supercapacitors have unique properties such as ultrafast charge-discharge behaviour, high power densities and very long-term stability compared to lithium-ion batteries [3-5]. Supercapacitors are typically classified into two main types depending on the charge storage mechanism utilised; electric double layer capacitors (EDLCs) and pseudocapacitors. In an EDLC, the electrical energy, in the form of

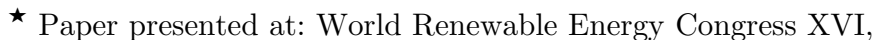
5-9 February 2017, Murdoch University, Western Australia.

* e-mail: shaymaaali77@gmail.com
}

free ions accumulated on the electrode surface, are stored by ion adsorption. In a pseudocapacitor that electrical energy is stored by fast surface redox reactions. With the acknowledgement that improving the performance of electrode materials is perhaps the best option for improving energy storage overall, a third type of 'hybrid' supercapacitor is emerging that stores the charge by both redox reaction and electrostatic phenomena occurring at the electrode/electrolyte interface. These 3rd wave electrodes promise high cell voltage, high specific capacitance, unmitigated cyclic stability, and improved energy density $[6-8]$.

In developing these new electrode materials researchers have found that enhancing surface area, electrical conductivity, providing short ion-diffusion pathways and having excellent interfacial integrity lead to desirable characteristics for applications ranging from use in electric vehicles to portable electronics [9-12]. Binary transition metal oxides (BTMOs), as opposed to simple transition metal oxides, can provide all of these characteristics and show particular promise for supercapacitor applications, particularly as they contain mixed metal valencies providing rich redox behaviour for exploitation. Two main challenges exist for the successful utilisation of BTMOs in hybrid electrochemical storage devices: producing particles 
Table 1. Summary of surface chemistry and electrochemical data for $\mathrm{NiCo}_{2} \mathrm{O}_{4}$ electrode materials. Bold values represent the best performing material.

\begin{tabular}{|c|c|c|c|c|c|c|c|}
\hline & Blank & & & \multicolumn{2}{|c|}{ ESM templated } & \multicolumn{2}{|c|}{ PMMA templated } \\
\hline \multirow{6}{*}{ XPS } & \multirow[b]{2}{*}{ Ni $2 p$} & $855 \mathrm{eV}$ & $\mathrm{Ni}^{+2}$ & & & & \\
\hline & & $874 \mathrm{eV}$ & $\mathrm{Ni}^{+3}$ & & & & \\
\hline & & $780 \mathrm{eV}$ & $\mathrm{Co}^{+2}$ & & & & \\
\hline & Co $2 p$ & $796 \mathrm{eV}$ & $\mathrm{Co}^{+3}$ & & & & \\
\hline & & $529 \mathrm{eV}$ & $\mathrm{O} 1$ & & & & \\
\hline & $\mathrm{O} 1 \mathrm{~s}$ & $531 \mathrm{eV}$ & $\mathrm{O} 2$ & & & & \\
\hline \multirow[t]{2}{*}{ Surface area $\left(\mathrm{m}^{2} \cdot \mathrm{g}^{-1}\right)$} & & 0.43 & & \multicolumn{2}{|c|}{7.34} & \multicolumn{2}{|c|}{20.91} \\
\hline & Average & \multicolumn{2}{|l|}{ Range } & Average & Range & Average & Range \\
\hline Pore size $(\mathrm{nm})$ & 14 & $5-50$ & & 15 & $5-50$ & 50 & $5-50$ \\
\hline Capacitance $\left(\mathrm{F} \cdot \mathrm{g}^{-1}\right)$ & \multicolumn{3}{|c|}{25.39} & \multicolumn{2}{|c|}{28.19} & \multicolumn{2}{|c|}{38.03} \\
\hline
\end{tabular}

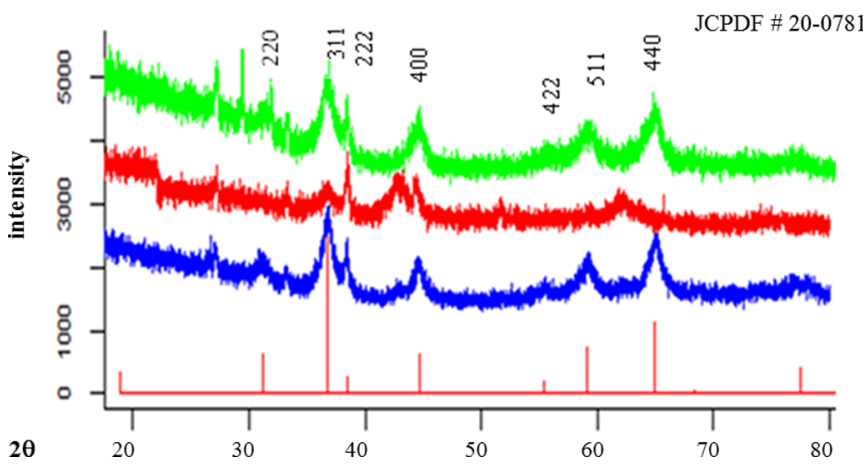

Fig. 1. XRD patterns for $\mathrm{NiCo}_{2} \mathrm{O}_{4}$ blank (blue), ESM templated (red), PMMA templated (green).

with sufficient surface area to complement the redox capabilities; and producing them from relatively cheap and environmentally benign metals.

The problem of surface area may be tackled by developing synthetic methods that produce intricate nano/meso scale structure or porosity in the BTMO that results in a dramatically increased surface area per particle, keeping in mind that ions still need to be able to access the surface, i.e. there is no point in having surface structure at a scale that is too small for ion migration to the surface [13-16]. One way to achieve this is to add a polymer template during the initial synthesis of the material. Using polymeric materials as templates may also result in improvements in the mechanical flexibility of the electrode, more reliable mesoporosity, and the capability to introduce pore shape and volume versatility depending on the polymer template utilised[17-19]. Many such templating agents exist with two of the more interesting being eggshell membrane (ESM) and poly methyl methacrylate (PMMA). The former has been suggested as a useful template due to its porous structure, high temperature of decomposition (over $200^{\circ} \mathrm{C}$ ), low water uptake and swelling properties[20]. In addition use of ESM could be viewed as re-use/valorisation of a product normally considered a waste. The PMMA has a much more regular (and potentially tunable) structure [19].
Nickel cobaltate $\left(\mathrm{NiCo}_{2} \mathrm{O}_{4}\right)$ has attracted considerable attention as a BTMO electrode material due to the relatively low cost of $\mathrm{Ni}$ and $\mathrm{Co}$, their environmental friendliness, and natural abundance $[21,22]$. Furthermore, the material possesses rich redox chemistry, electronic conductivity and electrochemical activity when compared to the corresponding simple metal oxides, $\mathrm{NiO}$ and $\mathrm{Co}_{3} \mathrm{O}_{4}[15,16,23]$. Examples of templated $\mathrm{NiCO}_{2} \mathrm{O}_{4}$ materials include an $\alpha-\mathrm{MnO}_{2} @ \mathrm{Ni}-$ $\mathrm{Co}_{2} \mathrm{O}_{4}$ core-shell heterostructure [24] and a hollow $\mathrm{NiCo}_{2} \mathrm{O}_{4}$ nanoparticle/graphene composite [25] but most $\mathrm{NiCo}_{2} \mathrm{O}_{4}$ materials presented in the literature do not use sacrificial templates as a means of increasing surface area, and particularly not polymeric templates.

The aim of this work was to determine if the addition of polymeric templates could increase the electrochemical capacitance of hydrothermally synthesised $\mathrm{NiCo}_{2} \mathrm{O}_{4}$.

\section{Methodology}

All chemicals were purchased from Sigma-Aldrich or Chem Supply. ESM was prepared by immersing natural eggshells in $2 \mathrm{M}$ nitric acid for $15 \mathrm{~min}$ then separating the thin membrane layer from shell, washing with deionized water (DI) twice and drying at $90^{\circ} \mathrm{C}$ for $2 \mathrm{~h}$.

Non-templated $\mathrm{NiCO}_{2} \mathrm{O}_{4}$ was synthesized via a hydrothermal process by dissolving $\mathrm{Ni}\left(\mathrm{NO}_{3}\right)_{2} \cdot 6 \mathrm{H}_{2} \mathrm{O}$ and $\mathrm{Co}$ $\left(\mathrm{NO}_{3}\right)_{2} \cdot 6 \mathrm{H}_{2} \mathrm{O}(2 \mathrm{mmol}: 4 \mathrm{mmol}$, respectively) into a mixed solution of ethanol and DI $(40 \mathrm{ml}$ each $)$ at room temperature. Urea $(24 \mathrm{mmol})$ was then added to the clear pink solution, the reaction mixture heated in an oven at $90^{\circ} \mathrm{C}$ for $8 \mathrm{~h}$ and cooled to room temperature. Finally, the solution was annealed at $400^{\circ} \mathrm{C}$ for $3 \mathrm{~h}$. Templated $\mathrm{NiCO}_{2} \mathrm{O}_{4}$ was synthesised by adding $(1 \mathrm{~g}, 1.5 \mathrm{~g}$, or $2.5 \mathrm{~g})$ of template (ESM or PMMA) to the above solution immediately prior to heating at $\left(90^{\circ} \mathrm{C}\right)$.

$\mathrm{NiCo}_{2} \mathrm{O}_{4}$ materials were characterized by SEM (JEOL JCM-6000) equipped with Energy-Dispersive X-ray spectroscopy (EDS) to determine surface composition. X-ray diffraction (XRD) data was collected $\left(2 \theta=20^{\circ}-80^{\circ}\right)$ with a GBC Scientific Equipment Enhanced Multi-Material Analyser (EMMA). Specific surface area and pore size 


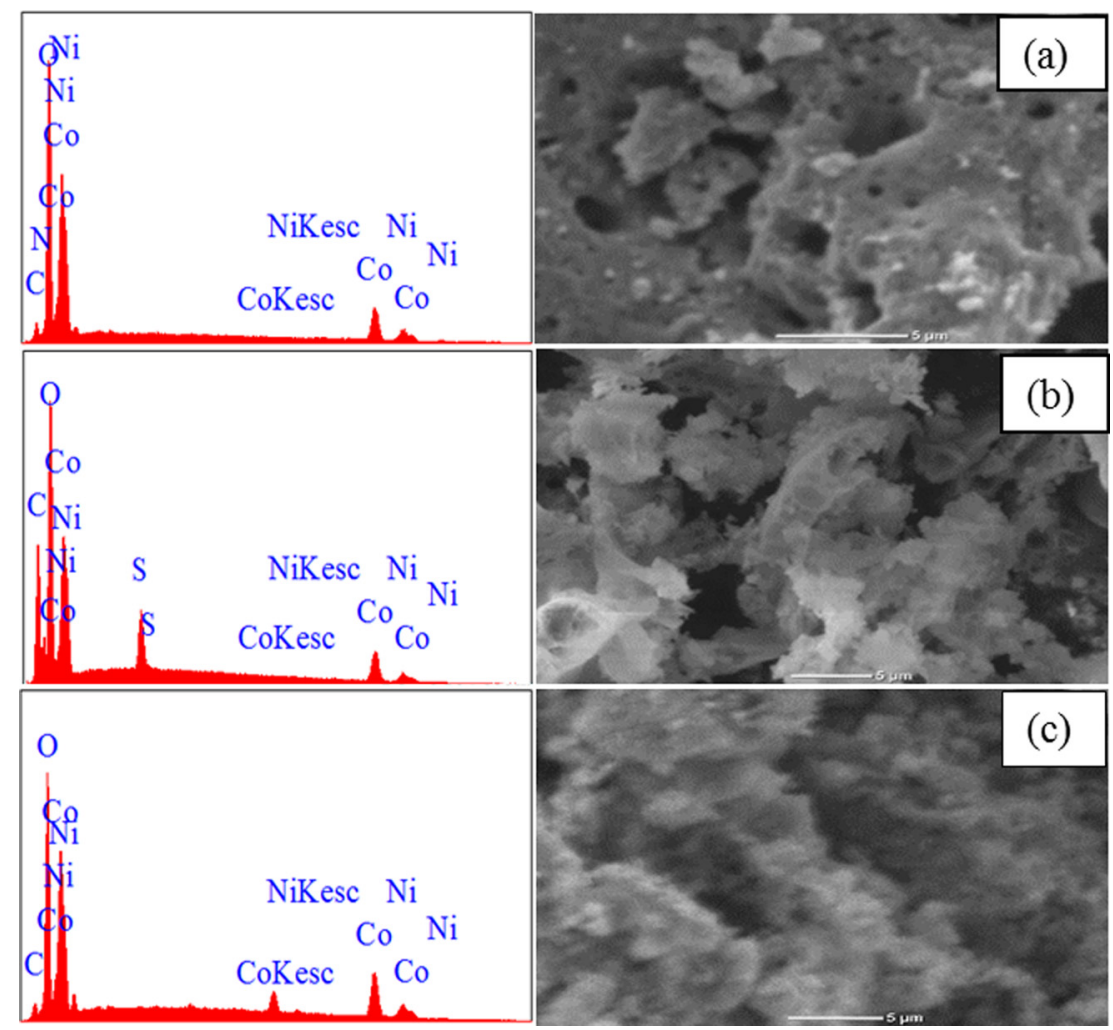

Fig. 2. SEM and EDS for $\mathrm{NiCO}_{2} \mathrm{O}_{4}$ blank (a), ESM template (b), PMMA template (c).

distribution were evaluated using Braunauere-EmmettTeller (BET) nitrogen $\left(\mathrm{N}_{2}\right)$ adsorption-desorption isotherms and Barrett-Joyner-Halenda (BJH) method, respectively, on a Micromeritics Tristar II surface area and porosity analyser. Fourier Transform Infrared Spectroscopy (FT-IR) was conducted using a Perkin Elmer Frontier FTIR/NIR equipped with a Universal ATR sampling accessory and analysed using Spectrum software, v10.4.2.

Electrochemical properties of the prepared samples were investigated by constructing a working electrode consisting of active materials (75 wt.\%), activated carbon (15 wt.\%), polyvinylidene fluoride binder (10 wt.\%), and Nmethyl-2-pyrrolidine $(250 \mu \mathrm{L})$. Ingredients were mixed to produce a homogenous paste which was coated onto a $\left(1 \mathrm{~cm}^{2}\right)$ graphite sheet. Cyclic voltammetry (CV) experiments were performed in $(2 \mathrm{M}) \mathrm{NaOH}$ electrolyte, using $\mathrm{Pt}$ wire and $\mathrm{Hg} / \mathrm{HgO}$ as the counter and reference electrodes in a three-electrode cell connected to a Princeton Applied Research versa STAT3. Galvanostatic charge-discharge was conducted using a two electrode cell (working electrode and activated carbon) in the potential range of $0.2-1.6 \mathrm{~V}$ at current of $1 \mathrm{~mA}$. Electrochemical behaviour was evaluated using Battery Analyser (MTI Corp, USA) operated by a battery testing system. Specific capacitance was calculated from galvanostatic charge-discharge curves using:

$$
C_{s}=\frac{I * \Delta t}{m * \Delta V}
$$

where $I$ is the constant discharge current (A), $\Delta t$ is the discharge time (s), $m$ is mass of the electroactive materials (g) and $\Delta V$ is the potential voltage $(\mathrm{V})$. The measured specific capacitances are shown in Table 1 for blank $\mathrm{NiCo}_{2} \mathrm{O}_{4}, \mathrm{NiCo}_{2} \mathrm{O}_{4}$ templated ESM and $\mathrm{NiCo}_{2} \mathrm{O}_{4}$ templated PMMA respectively.

\section{Results and discussion}

The prepared materials were identified as predominantly $\mathrm{NiCo}_{2} \mathrm{O}_{4}$ in a spinel conformation by comparison of XRD patterns with the standard recorded in the International Centre for Diffraction Data database standard (Fig. 1) and previously reported data $[8,23,26]$. There appears to be a small amount of contamination from $\mathrm{Ni}(\mathrm{OH})_{2}$ and $\mathrm{Co}_{3} \mathrm{O}_{4}$ in the templated materials. The XRD peaks are quite broad indicating a relatively amorphous material.

EDS of all materials (Fig. 2) indicated the presence of $\mathrm{Co}, \mathrm{Ni}$ and $\mathrm{O}$ on the surface with a $1: 2 \mathrm{Ni}$ to $\mathrm{Co}$ atomic ratio, consistent with the stoichiometric ratio of $\mathrm{NiCO}_{2} \mathrm{O}_{4}$ and those previously reported [27]. The chemical composition of the material surface was further elucidated by X-ray Photoelectron Spectra (XPS). This data (Tab. 1) provided further proof that the materials were $\mathrm{NiCo}_{2} \mathrm{O}_{4}$ and also showed that the $\mathrm{Ni}$ and $\mathrm{Co}$ are present in multivalent forms consistent with a spinel type structure. The Ni $2 p$ peak was composed of two spin-orbit doublets characteristic of $\mathrm{Ni}^{2+}$ $(855 \mathrm{eV})$ and $\mathrm{Ni}^{3+}(874 \mathrm{eV})[15,28]$ while the presence of $\mathrm{Co}^{2+}$ and $\mathrm{Co}^{3+}$ was indicated with major signals in the Co $2 \mathrm{p}$ peak at the binding energies of $780 \mathrm{eV}$ and $796 \mathrm{eV}$, respectively $[10,29]$. The presence of metal-oxygen bonds, consistent with formation of an oxide, was confirmed by a signal at $\sim 630 \mathrm{~cm}^{-1}$ in the FT-IR spectrum for each material $[18,30]$. 

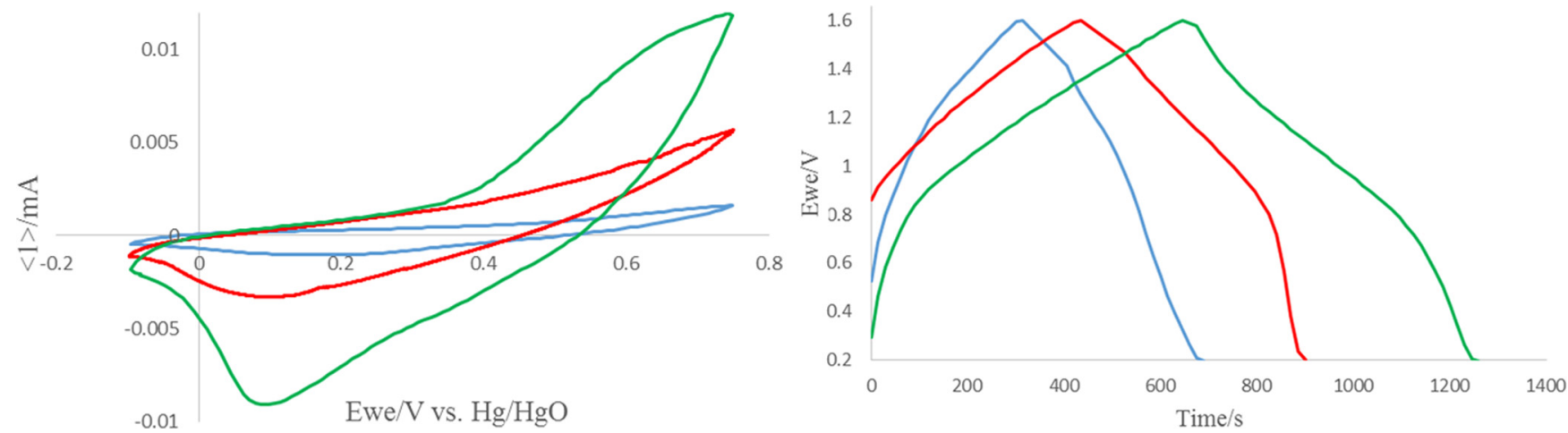

Fig. 3. CV curves (left) and CD behaviour (right) for $\mathrm{NiCo}_{2} \mathrm{O}_{4}$ blank (blue), ESM templated (red), PMMA templated (green).

The increased porosity of the templated materials was easily verified by SEM (Fig. 2) and confirmed by calculation of the specific surface area and pore size distribution (Tab. 1). The composites appear to be deposited as an irregular porous structure (as indicated by the XRD data) as observed in the $\mathrm{NiCo}_{2} \mathrm{O}_{4}$ ESM and PMMA template materials at high magnification. The $\mathrm{N}_{2}$ adsorption-desorption isotherms exhibited a hysteresis loop and analysis using the BET method showed that both template materials had a higher specific surface area than the blank material, with the PMMA template material having the largest surface area (50 times greater than the blank). The corresponding pore size distribution was calculated by the BJH method and confirmed that the ESM and PMMA samples exhibit a large pore volume and wellformed meso-porosity.

The electrochemical performance of the three synthesized $\mathrm{NiCo}_{2} \mathrm{O}_{4}$ materials was investigated by $\mathrm{CV}$ in a standard three-electrode cell and charge discharge (CD) methods using a 2 electrode configuration. The $\mathrm{CV}$ measurements showed a clear increase in redox behaviour with addition of the PMMA template (Fig. 3) as well as a dramatic increase in the peak current density. These results are mirrored in the $\mathrm{CD}$ data where the template materials clearly have a longer discharge time. The PMMA template material exhibits the best performance, as indicated by a doubling of the specific capacity compared with the nontemplated blank (Tab. 1).

Superior performance of the PMMA templated material appears to be due to an increase in surface area and a much larger average pore size. Comparison of the specific capacitance of the PMMA template $\mathrm{NiCO}_{2} \mathrm{O}_{4}$ is complicated due to difficulties in direct comparison of capacitance values derived from 2- and 3-electrode systems. However, an approximate conversion between the 2 electrode CD system to that expected for a 3 electrode CD system results a capacitance of $\sim 160 \mathrm{~F} \mathrm{~g}^{-1}$, a value that is comparable with other mesoporous hydrothermally produced $\mathrm{NiCo}_{2} \mathrm{O}_{4}$ reported in the recent review by Dubal et al. [31].

\section{Conclusions}

The inclusion of removable polymer templates improved the electrochemical performance of hydrothermally synthesised $\mathrm{NiCO}_{2} \mathrm{O}_{4}$. It appears that templating improved performance in two ways: increasing material porosity, i.e. increasing available surface area and; increasing pore size into the mesoporous range, allowing better access to the surface. The relatively ordered polymethylmethacrylate template produced better results than the fibrous, irregular eggshell membrane template. The measured specific capacity for the polymer templated material is similar to that reported for other porous $\mathrm{NiCo}_{2} \mathrm{O}_{4}$ materials produced using simple hydrothermal synthetic methods.

\section{References}

1. P. Ahuja, S.K. Ujjain, R.K. Sharma, G. Singh, Enhanced supercapacitor performance by incorporating nickel in manganese oxide, RSC Adv. 4, 57192 (2014)

2. R. Gokhale, V. Aravindan, P. Yadav, S. Jain, D. Phase, S. Madhavi, S. Ogale, Oligomer-salt derived 3D, heavily nitrogen doped, porous carbon for Li-ion hybrid electrochemical capacitors application, Carbon 80, 462 (2014)

3. J. Jiay, G. Tan, S. Peng, D. Qian, J. Liu, D. Luo, Y. Liu, Electrochemical performance of carbon-coated $\mathrm{Li}_{3} \mathrm{~V}_{2}\left(\mathrm{PO}_{4}\right)$ as a cathode material for a symmetric hybrid capacitor, Electrochim. Acta 107, 59 (2013)

4. T. Kim, A. Ramadoss, B. Saravanakumar, G.K. Veerasubramani, S.J. Kim, Synthesis and characterization of $\mathrm{NiCO}_{2} \mathrm{O}_{4}$ nanoplates as efficient electrode materials for electrochemical supercapacitors, Appl. Surf. Sci. 370, 452 (2016)

5. D. Cai, S. Xiao, D. Wang, B. Liu, L. Wang, Y. Liu, H. Li, Y. Wang, Q. Li, T. Wang, Morphology controlled synthesis of $\mathrm{NiCo}_{2} \mathrm{O}_{4}$ nanosheet array nanostructures on nickel foam and their application for pseudocapacitors, Electrochim. Acta 142, 118 (2014)

6. T. Wang, Y. Guo, B. Zhao, S. Yu, H.P. Yang, D. Lu, X.Z. Fu, R. Sun, C.P. Wong, $\mathrm{NiCo}_{2} \mathrm{O}_{4}$ nanosheets in-situ grown on three dimensional porous $\mathrm{Ni}$ film current collectors as integrated electrodes, J. Power Sources 286, 371 (2015)

7. M. Huang, W. Zhang, F. Li, L. Zhang, Z. Wen, Q. Liu, Facile synthesis of hierarchical $\mathrm{Co}_{3} \mathrm{O}_{4} @ \mathrm{MnO}_{2}$ core-shell arrays on $\mathrm{Ni}$ foam for asymmetric supercapacitors, J. Power Sources 252, 98 (2014)

8. K. Xu, J. Yang, S. Li, Q. Liu, J. Hu, Facile synthesis of hierarchical mesoporous $\mathrm{NiCO}_{2} \mathrm{O}_{4}$ nanoflowers with large specific surface area for high-performance supercapacitor, Mater. Lett. 10, 83 (2016) 
9. E.R. Ezeigwe, P.S. Khiew, C.W. Siong, M.T.T. Tan, Solvothermal synthesis of $\mathrm{NiCO}_{2} \mathrm{O}_{4}$ nanocomposites on liquid-phase exfoliated graphene as an electrode material for electrochemical capacitors, J. Alloys Compd. 693, 1133 (2017)

10. Y. Zhang, L. Li, H. Su, W. Huang, X. Dong, Binary metal oxide: advanced energy storage materials in supercapacitors, J. Mater. Chem. A 3, 43 (2015)

11. J. Cho, S. Jeong, Y. Kim, Commercial and research battery technologies for electrical energy storage applications, Progr. Energy Combust. Sci. 48, 84 (2015)

12. X. Han, T. Ji, Z. Zhao, H. Zhang, Economic evaluation of batteries planning in energy storage power stations for load shifting, Renew. Energy 78, 643 (2015)

13. Y. Tian, H. Li, Z. Ruan, G. Cui, S. Yan, Synthesis of $\mathrm{NiCO}_{2} \mathrm{O}_{4}$ nanostructures with different morphologies for the removal of methyl orange, Appl. Surf. Sci. 393, 434 (2017)

14. S. Sun, S. Li, S. Wang, Y. Li, L. Han, H. Kong, P. Wang, Fabrication of hollow $\mathrm{NiCO}_{2} \mathrm{O}_{4}$ nanoparticle/graphene composite for supercapacitor electrode, Mater. Lett. 182, $23(2016)$

15. J. Yang, M. Cho, Y. Lee, Synthesis of hierarchical $\mathrm{NiCo}_{2} \mathrm{O}_{4}$ hollow nanorods via sacrificial-template accelerate hydrolysis for electrochemical glucose oxidation, Biosens. Bioelectron. 75, 15 (2016)

16. E. Umeshbabu, G.R. Rao, $\mathrm{NiCo}_{2} \mathrm{O}_{4}$ hexagonal nanoplates anchored on reduced graphene oxide sheets with enhanced electrocatalytic activity and stability for methanol and water oxidation, Electrochim. Acta 213, 717 (2016)

17. D. Dong, Y. Wu, X. Zhang, J. Yao, Y. Huang, D. Li, C.Z. Li, Eggshell membrane-template synthesis of highly crystalline perovskite ceramics for solid oxide fuel cells, J. Mater. Chem. 21, 1028 (2010)

18. P. He, B. Chen, Y. Wang, Z. Xie, F. Dong, Preparation and characterization of a novel organophilic vermiculite/poly (methyl methacrylate)/1-butyl-3-methylimidazolium hexafluoro phosphate composite gel polymer electrolyte, Electrochem. Acta 111, 108 (2013)

19. E.P. Grishina, L.M. Ramenskaya, A.N. Mudrov, Conductivity and dielectric properties of heterogeneous films based on homoand copolymers of methyl (methacrylate) and vinyl pyrrolidone doped with ionic liquid, Eur. Polym. J. 59, 247 (2014)

20. M. Balaz, Eggshell membrane biomaterial as a platform for applications in materials science, Acta Biomater. 10, 3827 (2014)
21. B. Ge, K. Li, Z. Fu, L. Pu, X. Zhang, Z. Liu, K. Huang, The performance of nano urchin-like $\mathrm{NiCO}_{2} \mathrm{O}_{4}$ modified activated carbon as air cathode for microbial fuel cell, J. Power Sources 303, 325 (2016)

22. R. Ding, L. Qi, M. Jia, H. Wang, Facile and large-scale chemical synthesis of highly porous secondary submicron/ micron-sized $\mathrm{NiCo}_{2} \mathrm{O}_{4}$ materials for high-performance aqueous hybrid $\mathrm{AC}-\mathrm{NiCO}_{2} \mathrm{O}_{4}$ electrochemical capacitors, Electrochim. Acta 107, 494 (2013)

23. J. Pu, J. Wang, X. Jin, F. Cui, E. Sheng, Z. Wang, Porous hexagonal $\mathrm{NiCo}_{2} \mathrm{O}_{4}$ nanoplates as electrode materials for supercapacitors, Electrochim. Acta 106, 226 (2013)

24. Z. Ma, G. Shao, Y. Fan, M. Feng, D. Shen, H. Wang, Fabrication of high-performance all-solid-state asymmetric supercapacitors based on stable $\alpha-\mathrm{MnO}_{2} @ \mathrm{NiCo}_{2} \mathrm{O}_{4}$ core-shell heterostructure and 3D-nanocage $\mathrm{N}$-doped porous carbon, Sustain. Chem. Eng. 5, 4865 (2017)

25. M. Yao, N. Wang, J. Yin, W. Hu, Mesoporous three dimension $\mathrm{NiCo}_{2} \mathrm{O}_{4}$ /graphene composites fabricated by selfgenerated sacrificial template method for a greatly enhanced specific capacity, J. Mater. Sci.: Mater. Electron. 28, 11119 (2017). Doi: 10.1007/s10854-017-6898-2

26. Y.Z. Su, Q.Z. Xu, G.F. Chen, H. Cheng, N. Li, Z.Q. Liu, One dimensional spinel $\mathrm{NiCo}_{2} \mathrm{O}_{4}$ nanowire arrays: facile synthesis, water oxidation, and magnetic properties, Electrochim. Acta 174, $1216(2015)$

27. Y. Zhang, J. Wang, L. Yu, L. Wang, P. Wan, H. Wei, L. Lin, S. Hussain, $\mathrm{Ni@NiCo} \mathrm{N}_{4}$ core/shells composite as electrode material for supercapacitor, Ceram. Int. 43, 2057 (2015)

28. A. Shanmugavani, R.K. Selvan, Microwave assisted reflux synthesis of $\mathrm{NiCo}_{2} \mathrm{O}_{4} / \mathrm{NiO}$ composite: fabrication of high performance asymmetric supercapacitor with $\mathrm{Fe}_{2} \mathrm{O}_{3}$, Electrochim. Acta 189, 283 (2016)

29. R. Ding, L. Qi, H. Wang, An investigation of spinel $\mathrm{NiCo}_{2} \mathrm{O}_{4}$ as anode for Na-ion capacitors, Electrochim. Acta 114, 726 (2013)

30. M.K. Rath, B.H. Choi, M.J. Ji, K.T. Lee, Eggshellmembrane-template synthesis of hierarchically-ordered NiO-Ce ${ }_{0.8} \mathrm{Gd}_{0.2} \mathrm{O}_{1.9}$ composite powders and their electrochemical performances as SOFC anodes, Ceram. Int. 40, 3295 (2014)

31. D.P. Dubal, P. Gomez-Romero, B.R. Sankapal, R. Holze, Nickel cobaltite as an emerging material for supercapacitors: an overview, Nano Energy 11, 377 (2015)

Cite this article as: Shaymaa Albohani, Manickam Minakshi Sundaram, Damian W. Laird, Polymer templated nickel cobaltate for energy storage, Renew. Energy Environ. Sustain. 2, 9 (2017) 